\title{
One Shot Six Centres: A New Strategy in Ultrasound Guided Paravertebral Block
}

\section{Benedetta Galli, Dario Cappiello and Massimiliano Carassiti*}

Department of Anaesthesia, Institution Campus Bio Medico, University School of Medicine, Rome, Italy

${ }^{*}$ Corresponding author: Massimiliano Carassiti, Department of Anaesthesia, Institution Campus Bio Medico, University School of Medicine, Rome, Italy, Tel: +39-06-225411181; E-mail: m.carassiti@unicampus.it

Received date: July 23, 2014; Accepted date: Nov 27, 2015; Published date: Nov 30, 2015

Copyright: ( 2015 Galli B, et al. This is an open-access article distributed under the terms of the Creative Commons Attribution License, which permits unrestricted use, distribution, and reproduction in any medium, provided the original author and source are credited.

\begin{abstract}
The paravertebral block (PVB) is the technique of injecting local anaesthetic alongside the vertebral body close to where the spinal nerves emerge from the intervertebral foramen. This produces unilateral, segmental, somatic, and sympathetic nerve blockade in multiple contiguous thoracic dermatomes which is effective for managing acute and chronic pain. Recently PVB has also been used for surgical anaesthesia in patients undergoing several surgical procedures with improved postoperative outcomes. Unfortunately the spread of local anaesthetic and the anaesthetic effect is sometime unpredictable, even with a standardized ultrasound-guided technique. The aim of this study is to show a new approach for the Paravertebral block ultrasound-guided and confirmed by ENS using a single injection. This new approach allows an easy visualization and accurate puncture of the paravertebral space, ensuring good anaesthesia of reproducibility, productivity and effectiveness. In this study we obtained six dermatomes anaesthesia, with a single shot injection in all patients.
\end{abstract}

Keywords: Paravertebral block; Ultrasound in regional anesthesia

\section{Introduction}

Paravertebral blocks were initially described in the early twentieth century and their use was reintroduced in 1979 by Eason and Wyatt $[1,2]$. Over the past 15 years paravertebral block has generated significant interest for the management of patients undergoing thoracic and abdominal surgical procedures. Several studies support the hypothesis that PVB are effective as epidural blocks for perioperative pain management without many of the side effects of neur-axial techniques [3-6]. Moreover the use of paravertebral block has been shown to delay the recurrence of tumours and the development of metastases in a retrospective analysis [7]. The thoracic paravertebral space (TPVS) is a wedge-shaped space located on either side of the vertebral column. Anterolateral it is limited by the pleura (PP) while the superior costotransverse ligament (SCL), forms the posterior border. The base of the wedge is formed by the posterolateral surface of the vertebral body, intervertebral disk, and the intervertebral foramen. Interposed between the PP and the SCL there is a fibro elastic structure: the "endo thoracic fascia". The TPVS communicates with the contiguous space above and below, the epidural space medially, the intercostal space laterally, the contralateral paravertebral space via the prevertebral and epidural route, and inferiorly with the retroperitoneal space posterior to the fascia transversalis. The most frequent indication for paravertebral blocks is perioperative management of pain for breast surgery [8-11] lithotripsy [12], minor abdominal surgery [13] and pelvic surgery [14], major abdominal surgery [15-17], VATS [16] and open thoracotomy [18-20]. Other than the data described [21], the author is not aware of any other published data describing different techniques to perform a real-time US pvb in the clinical setting. An ultrasound scan for PVB can be performed in the transverse (axial scan) or longitudinal (sagittal scan) axis with the patient in the sitting, lateral decubitus, or prone position. The prone position is useful in patients presenting for a chronic pain procedure when fluoroscopy may also be used in conjunction with ultrasound imaging. Currently, there are no data demonstrating an optimal axis for the scan or the intervention. It is often a matter of individual preference and experience. In our daily practice we have developed a new technique that allows us an optimal vision of the structures of the paravertebral region using an in-plane approach and rotating the probe gently until it is parallel to the coasts (Figure 1), as already described in a study on cadavers [22]. Our aim was also to predict the distribution of the anaesthetic, a previously unsolved problem, using the technique of mixed US\ENS, to get a block that is as reproducible as possible.

\section{Methods}

After obtaining Institutional Ethical Committee approval and the patients' written informed consent, 34 patients aged between 50 and 80 years, ASA physical status ASA I- III who were scheduled to undergo thermo ablation for liver metastasis, quadrantectomy and open lung surgery were enrolled in the study. After application of routine monitoring and supplemental oxygen, all patients received midazolam $1 \mathrm{mg}$ IV. A dose of $0.4 \mathrm{ml} / \mathrm{kg}$ of LA was prepared by of using $0.5 \%$ ropivacaine. Skin asepsis and sterile draping were performed, and the US probe was sheathed. All blocks were performed by one experienced anaesthesiologist. The probe (Esaote MyLab 25, transducer LA523E with frequency band 5-10 MHz) was placed at the spinous process, where it was possible to recognize the transverse process by the typical cone shadow. After localizing the pleura, the probe was rotated 30 degrees, parallel to the ribs. Then the lateral costo-transverse ligament was visualized above the pleura. A 21 Stimuplex needle (B. Braun Medical Milano S.P.A. Italy) was inserted and visualized in-plane. Once the lateral costo-transverse ligament was passed, the electroneuro-stimulator (stimuplex HNS12 B Braun) was turned on, and when muscle contractions were aroused at $0.5 \mathrm{~mA}$, ropivacaine was injected. The correct diffusion of the local anaesthetic was visualized through ultrasounds when the typical detachment of the parietal pleura from the rib cage was obtained. The block extension 
was assessed by ice test and prick tests. The timing block (visualization and injection), success rate, onset time, dose of local anaesthetic, nausea and vomiting and any other complications were recorded. The timing block was defined as the time from the placement of the US probe on the patient (the time for skin preparation, draping, and probe sheathing was not included) to complete the anaesthetic injection around the nerve. Before discharge, the patients fill in a multiple choice questionnaire on the degree of satisfaction on a scale from 1-6(1 being "not satisfied" and 6 "Extremely satisfied").

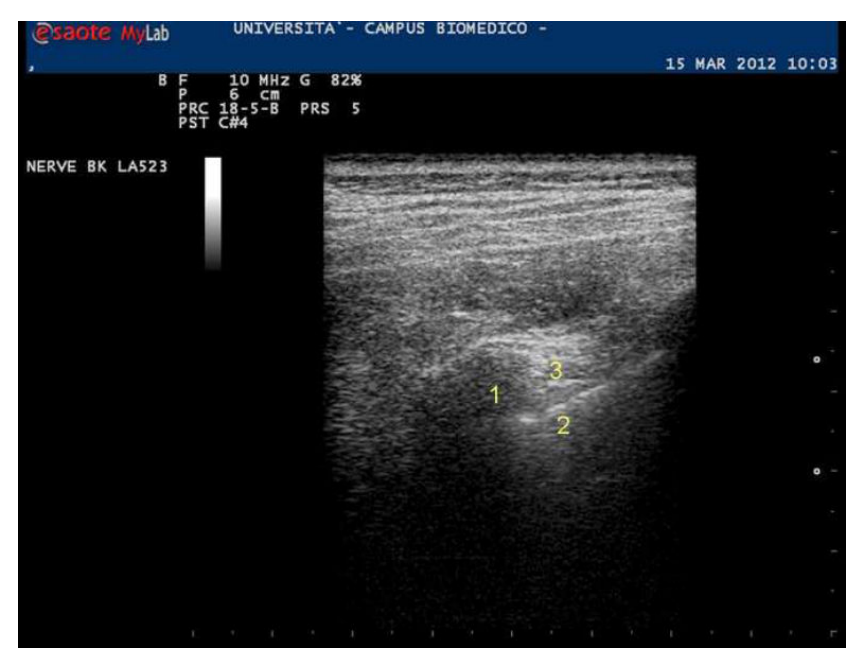

Figure 1: Ultrasound image of the paravertebral space with the probe rotated of thirty degrees: the transverse process 1) is identifiable by the typical cone shadow, the pleura 2) and the costotransverse ligament 3 ) visualized above the pleura.

\section{Results}

34 Pvt Blocks were registered. Patient demographics are summarized in Table 1. In all patients a correct visualization of the space and of the needle was obtained in less than $4 \min (228 \pm 132$ $\mathrm{sec})$. The median dose of local anaesthetic was $(123 \mathrm{mg} \pm 21.1)$. The procedure was always well tolerated, with a complete anaesthesia 30 minutes after the injection in all cases (100\%). Complete anaesthesia of six dermatomers was reached in $100 \%$ of patients. We have experienced an accidental bilateral block in one patient, without any consequences. No patient experienced nausea and vomiting. None of the patients complained about pain or discomfort and all were overall extremely satisfied. Complications associated to the paravertebral block were one vagal crisis during procedure (2.9\%), and one episode of bilateral block (2.9\%).

\begin{tabular}{|l|l|l|}
\hline Age (Mean $\pm \mathbf{y r})$ & Weight $\mathbf{( k g )}$ & Height $\mathbf{( c m})$ \\
\hline $69 \pm 9.3$ & $70 \pm 11.6$ & $164.2 \pm 7.7$ \\
\hline
\end{tabular}

Table 1: Demographics data

\section{Discussion}

In this investigation, our group has demonstrated objectively that the ultrasound visibility of the SCL, the paravertebral space, and the pleura is better when the ultrasound beam is oriented in a slightly oblique axis, i.e., with the ultrasound transducer tilted slightly laterally or outward [22]. Although the spread of LA was reproducible [23], the anaesthetic effect was unpredictable, even with a standardized ultrasound-guided technique in volunteers. While it can be assumed that approximately four vertebral levels are covered by $20 \mathrm{ml} \mathrm{LA}$, the somatic distribution of the pvt remains unpredictable [23]. In a significant number of cases, the LA distributes into the epidural space, prevertebral, or to the contralateral side. That's why we use US/Ens guided technique to predict the distribution of the anaesthetic and the puncture behind the endo-thoracic fascia to get a longitudinal anaesthetic distribution [23,24]. We obtained reproducible anaesthesia in six dermatomers with a single injection in all patients. Previous studies showed that the most common difficulty performing ultrasound guided block is the visualization of the needle tip during its progress. For this reason, in our study we chose to direct the probe rotated to 30 degrees, aligning it with the ribs. Rotating the probe allows an easier visualization of the costo-transverse ligament and of the top of the paravertebral space, granting an optimal visual field for the in-plane approach with a latero-medial direction. Although the needle was always perfectly visualized with this approach, we stimulated a local response through the ENS technique. Electro-neurostimulation allows a more objective evaluation of the needle distance from the spinal nerves and, according with Naya, we may suppose that the voltage $<0.5 \mathrm{~mA}$ indicates the needle is positioned ventral to the endothoracic fascia; so we are able to foresee the anaesthetic multi segmental longitudinal distribution pattern and, as a consequence, to reduce the rate of failure and dis homogeneous distribution. Finally, the 30 degrees echo graphic section provides a better acoustic window, granting a higher safety while approaching with the needle. Our study allowed us to obtain an adequate anaesthesia and analgesia in $100 \%$ of the patients, through a single paravertebral puncture. In conclusion, we successfully developed a technique for an Ens/ultrasound-guided puncture of the paravertebral space. This new approach allows an easy visualization and accurate puncture of the paravertebral space, ensuring good reproducibility, productivity and effectiveness, with rare and minor complications.

\section{Conflict of Interest}

The authors declare that there is no conflict of interest.

\section{References}

1. Karmakar MK (2001) Thoracic paravertebral block. See comment in PubMed Commons below Anesthesiology 95: 771-780.

2. Vila H Jr, Liu J, Kavasmaneck D (2007) Paravertebral block: new benefits from an old procedure. See comment in PubMed Commons below Curr Opin Anaesthesiol 20: 316-318.

3. Joshi GP, Bonnet F, Shah R, Wilkinson RC, Camu F, et al. (2008) A systematic review of randomized trials evaluating regional techniques for postthoracotomy analgesia. See comment in PubMed Commons below Anesth Analg 107: 1026-1040.

4. Kotzé A, Scally A, Howell S (2009) Efficacy and safety of different techniques of paravertebral block for analgesia after thoracotomy: a systematic review and metaregression. See comment in PubMed Commons below Br J Anaesth 103: 626-636.

5. Richardson J, Sabanathan S, Jones J, Shah RD, Cheema S, et al. (1999) A prospective, randomized comparison of preoperative and continuous balanced epidural or paravertebral bupivacaine on post-thoracotomy pain, pulmonary function and stress responses. See comment in PubMed Commons below Br J Anaesth 83: 387-392.

6. Exadaktylos AK, Buggy DJ, Moriarty DC, Mascha E, Sessler DI (2006) Can anesthetic technique for primary breast cancer surgery affect 
recurrence or metastasis? See comment in PubMed Commons below Anesthesiology 105: 660-664.

7. Davies RG, Myles PS, Graham JM (2006) A comparison of the analgesic efficacy and side-effects of paravertebral vs epidural blockade for thoracotomy--a systematic review and meta-analysis of randomized trials. See comment in PubMed Commons below Br J Anaesth 96: 418-426.

8. Cooter RD, Rudkin GE, Gardiner SE (2007) Day case breast augmentation under paravertebral blockade: a prospective study of 100 consecutive patients. See comment in PubMed Commons below Aesthetic Plast Surg 31: 666-673.

9. Greengrass R, O'Brien F, Lyerly K, Hardman D, Gleason D, et al. (1996) Paravertebral block for breast cancer surgery. See comment in PubMed Commons below Can J Anaesth 43: 858-861.

10. Pusch F, Freitag H, Weinstabl C, Obwegeser R, Huber E, et al. (1999) Single-injection paravertebral block compared to general anaesthesia in breast surgery. See comment in PubMed Commons below Acta Anaesthesiol Scand 43: 770-774.

11. Jamieson BD, Mariano ER (2007) Thoracic and lumbar paravertebral blocks for outpatient lithotripsy. See comment in PubMed Commons below J Clin Anesth 19: 149-151.

12. Hadzic A, Kerimoglu B, Loreio D, Karaca PE, Claudio RE, et al. (2006) Paravertebral blocks provide superior same-day recovery over general anesthesia for patients undergoing inguinal hernia repair. See comment in PubMed Commons below Anesth Analg 102: 1076-1081.

13. Ben-David B, Swanson J, Nelson JB, Chelly JE (2007) Multimodal analgesia for radical prostatectomy provides better analgesia and shortens hospital stay. See comment in PubMed Commons below J Clin Anesth 19: 264-268.

14. Finnerty O, Carney J, McDonnell JG (2010) Trunk blocks for abdominal surgery. See comment in PubMed Commons below Anaesthesia 65 Suppl 1: 76-83.

15. Culp WC Jr, Culp WC (2005) Thoracic paravertebral block for percutaneous transhepatic biliary drainage. See comment in PubMed Commons below J Vasc Interv Radiol 16: 1397-1400.
16. Culp WC, McCowan TC, DeValdenebro M, Wright LB, Workman JL, et al. (2006) Paravertebral block: an improved method of pain control in percutaneous transhepatic biliary drainage. See comment in PubMed Commons below Cardiovasc Intervent Radiol 29: 1015-1021.

17. Kaya FN, Turker G, Basagan-Mogol E, Goren S, Bayram S, et al. (2006) Preoperative multiple-injection thoracic paravertebral blocks reduce postoperative pain and analgesic requirements after video-assisted thoracic surgery. See comment in PubMed Commons below J Cardiothorac Vasc Anesth 20: 639-643.

18. Català E, Casas JI, Unzueta MC, Diaz X, Aliaga L, et al. (1996) Continuous infusion is superior to bolus doses with thoracic paravertebral blocks after thoracotomies. See comment in PubMed Commons below J Cardiothorac Vasc Anesth 10: 586-588.

19. Daly DJ, Myles PS (2009) Update on the role of paravertebral blocks for thoracic surgery: are they worth it? See comment in PubMed Commons below Curr Opin Anaesthesiol 22: 38-43.

20. De Cosmo G, Aceto P, Gualtieri E, Congedo E (2009) Analgesia in thoracic surgery: review. See comment in PubMed Commons below Minerva Anestesiol 75: 393-400.

21. Atlas of Ultrasound-Guided Procedures in Interventional Pain Management; (2012) Samer N. Narouze, MD, MSc, DABPM, FIPP. Springer

22. Luyet C, Eichenberger U, Greif R, Vogt A, Szücs Farkas Z, et al. (2009) Ultrasound-guided paravertebral puncture and placement of catheters in human cadavers: an imaging study. See comment in PubMed Commons below Br J Anaesth 102: 534-539.

23. Marhofer D, Marhofer P, Kettner SC, Fleischmann E, Prayer D, et al (2013) Magnetic resonance imaging analysis of the spread of local anesthetic solution after ultrasound-guided lateral thoracic paravertebral blockade: a volunteer study. See comment in PubMed Commons below Anesthesiology 118: 1106-1112.

24. Voscopoulos C, Palaniappan D, Zeballos J, Ko H, Janfaza D, et al. (2013) The ultrasound-guided retrolaminar block. See comment in PubMed Commons below Can J Anaesth 60: 888-895. 